\title{
Effect of Temperature on Ion Conductive Behavior in Poly(propylene oxide) Solution of $\mathrm{LiClO}_{4}$
}

\author{
Masayoshi WATANABE,* Junko IKEDA, and Isao SHINOHARA \\ Department of Polymer Chemistry, Waseda University, \\ Ohkubo, Shinjuku-ku, Tokyo 160, Japan
}

(Received August 11, 1982)

KEY WORDS Polymeric Ion Conductor / Polymeric Solvent / Poly(propylene oxide) (PPO) / $\mathrm{LiClO}_{4} /$ Viscosity / Equivalent Conductance /

In order to make polymeric ion conductors, it is important to generate a good many ionic carriers in a polymer and simultaneously obtain a high mobility of generated carriers.

Our attention has been directed to the fact that polyethers such as poly(ethylene oxide) ${ }^{1}$ and poly(propylene oxide) (PPO) ${ }^{2,3}$ dissolve many inorganic salts present in high concentrations. We found ${ }^{4}$ that an electrolyte solution using one of these polymers as a solvent, e.g., PPO solution of $\mathrm{LiClO}_{4}$, has ionic conductivity of $10^{-4}-10^{-6} \mathrm{Scm}^{-1}$ at room temperature. In this solution, the electrical conductivity is induced by many ionic carriers generated as a result of solvation of the polar and flexible PPO main chain to $\mathrm{LiClO}_{4}$ and also by migration of these carriers against the viscosity of the solution. The large increase in viscosity with an increase in salt concentration greatly affects ion conductive behavior in this solution. The equivalent conductance is influenced not only by such a viscosity change but also by the molecular weight of PPO. It was also found ${ }^{5}$ that solidified films made from this electrolyte solution by blockcopolymerization give polymeric solid electrolytes with ionic conductivity of $10^{-7}-10^{-10} \mathrm{Scm}^{-1}$ at $20^{\circ} \mathrm{C}$.

In this paper we report on the effects of temperature on ion conductive behavior in a PPO solution of $\mathrm{LiClO}_{4}$. This behavior was examined by consideration of the relation between the equivalent conductance $(\mu)$ and viscosity $(\eta)$ of the electrolyte solutions. This relation has been investigated ${ }^{6}$ in ordinary polymers containing no dissolved salts. Since the quantitative amount of $\mathrm{LiClO}_{4}$ could be dissolved in PPO, the influence of the salt concentration on the $\mu-\eta$ relation was also investigated.

PPO $2000(\mathrm{~mol} \mathrm{wt}=2020)$ was used as a polymeric solvent. Volatile compounds in PPO were evaporated under reduced pressure. A desired PPO solution of $\mathrm{LiClO}_{4}$ was prepared first by dissolving anhydrous $\mathrm{LiClO}_{4}$ and PPO in methanol and then evaporating methanol completely under reduced pressure. The concentration of $\mathrm{LiClO}_{4}$ in the electrolyte solutions was represented by the molar ratio of $\mathrm{LiClO}_{4}$ to the repeating unit of PPO $\left(\left[\mathrm{LiClO}_{4}\right] /\right.$ [PO unit]). The conductivity of the electrolyte solution was measured with a Toa-Electronics CM$20 \mathrm{~A}$ digital conductometer at $50 \mathrm{~Hz}$. The viscosity of the electrolyte solution was measured with a Shibaura Systems Vismetron VSA-L viscometer. The temperature for measurement was controlled by a thermoregulator.

Figure 1 shows the relation between conductivity $(\sigma)$ and $\left[\mathrm{LiClO}_{4}\right] /[\mathrm{PO}$ unit $]$ at various temperatures. In the absence of $\mathrm{LiClO}_{4}$, the temperature dependence of $\sigma$ in PPO was small, and $\sigma$ was of the order of $10^{-9} \mathrm{Scm}^{-1}$. The values of $\sigma$ of the electrolyte solutions ranged from $10^{-7} \mathrm{Scm}^{-1}$ to $10^{-4} \mathrm{Scm}^{-1}$, and increased with an increase in temperature. The change in $\sigma$ with an increase in $\left[\mathrm{LiClO}_{4}\right] /[\mathrm{PO}$ unit $]$ showed a maximum. The concentration at the maximum $\sigma$ increased with an increase in temperature. At high concentrations, the decrease in $\sigma$ became less as the temperature

\footnotetext{
* Present address: Department of Chemistry, Sophia University, Kioi-cho, Chiyoda-ku, Tokyo 102, Japan.
} 


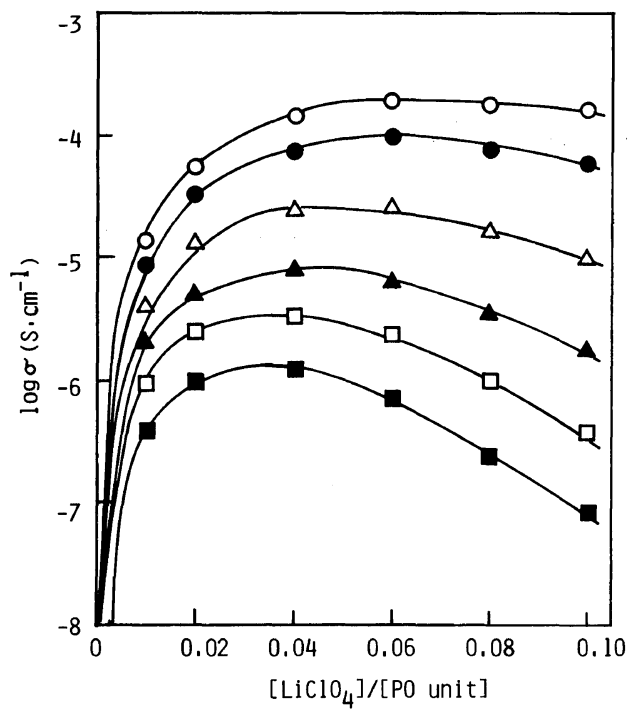

Figure 1. Relation between conductivity $(\sigma)$ and $\left[\mathrm{LiClO}_{4}\right] /\left[\mathrm{PO}\right.$ unit] in PPO 2000 solution of $\mathrm{LiClO}_{4}^{\circ}: \mathbf{\square}$, $5^{\circ} \mathrm{C} ; \square, 15^{\circ} \mathrm{C} ; \Delta, 25^{\circ} \mathrm{C} ; \triangle, 40^{\circ} \mathrm{C} ; \bigcirc, 60^{\circ} \mathrm{C} ; \bigcirc, 75^{\circ} \mathrm{C}$.

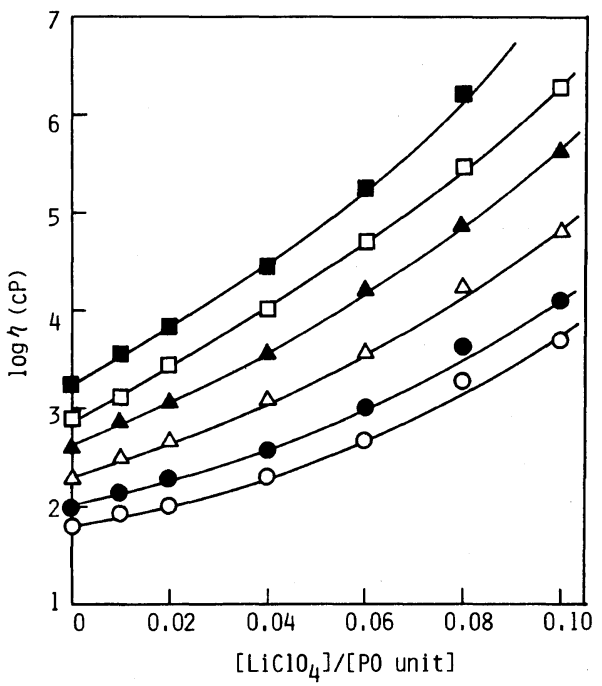

Figure 2. Relation between viscosity $(\eta)$ and $\left[\mathrm{LiClO}_{4}\right] /\left[\mathrm{PO}\right.$ unit] in PPO 2000 solution of $\mathrm{LiClO}_{4}$ : $5^{\circ} \mathrm{C} ; \square, 15^{\circ} \mathrm{C} ; \Delta, 25^{\circ} \mathrm{C} ; \triangle, 40^{\circ} \mathrm{C} ; \bigcirc, 60^{\circ} \mathrm{C} ; \bigcirc, 75^{\circ} \mathrm{C}$.

increased.

Figure 2 shows the relation between viscosity $(\eta)$ and $\left[\mathrm{LiClO}_{4}\right] /[\mathrm{PO}$ unit]. With an increase in $\left[\mathrm{LiClO}_{4}\right] /[\mathrm{PO}$ unit], $\eta$ increased greatly. PPO solvates and dissociates $\mathrm{LiClO}_{4}$. The solvation of ether oxygen atoms in PPO to the ions provides transient

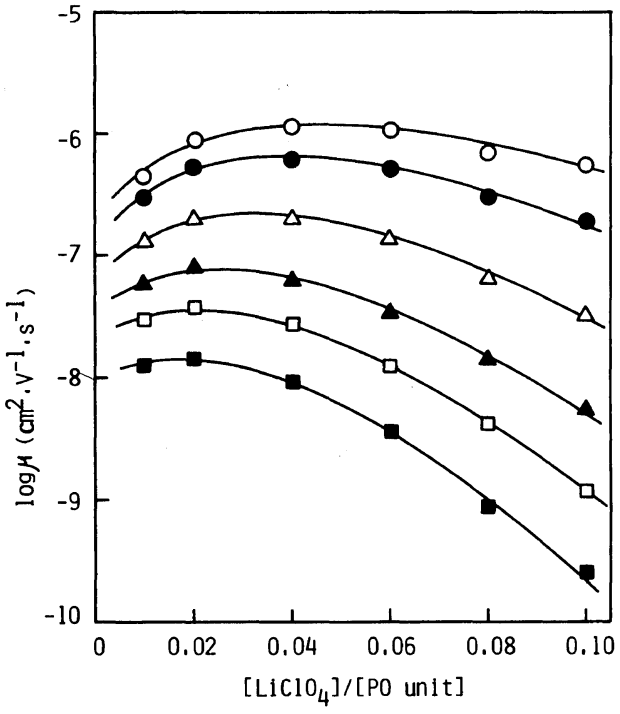

Figure 3. Relation between equivalent conductance $(\mu)$ and $\left[\mathrm{LiClO}_{4}\right] /\left[\mathrm{PO}\right.$ unit] in PPO 2000 solution of $\mathrm{LiClO}_{4}$ : $\square, 5^{\circ} \mathrm{C} ; \square, 15^{\circ} \mathrm{C} ; \Delta, 25^{\circ} \mathrm{C} ; \triangle, 40^{\circ} \mathrm{C} ; \bigcirc, 60^{\circ} \mathrm{C} ; \bigcirc, 75^{\circ} \mathrm{C}$.

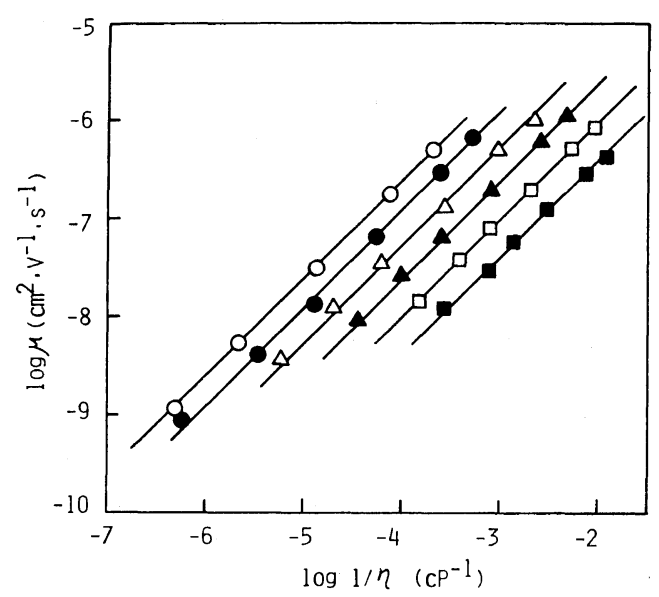

Figure 4. Relation between equivalent conductance $(\mu)$ and reciprocal of viscosity $(1 / \eta)$ in PPO 2000 solution of $\mathrm{LiClO}_{4} \cdot\left[\mathrm{LiClO}_{4}\right] /[\mathrm{PO}$ unit]: $\square, 0.01 ; \square, 0.02 ; \boldsymbol{\Delta}, 0.04$; $\triangle, 0.06 ; 0,0.08 ; \bigcirc, 0.10$.

crosslinking points between $\mathrm{PO}$ units, and gives rise to increased viscosity. The values of $\eta$ decreased with an increase in temperature. The amount of increase in $\eta$ with $\left[\mathrm{LiClO}_{4}\right] /[\mathrm{PO}$ unit $]$ decreased with rise in temperature.

The equivalent conductance $(\mu)$ of the electrolyte solution was calculated from 


$$
\mu=\frac{\sigma V\left(\left[\mathrm{LiClO}_{4}\right] /[\mathrm{PO} \text { unit }] M_{\mathrm{L}}+M_{\mathrm{P}}\right)}{2 e N\left[\mathrm{LiClO}_{4}\right] /[\mathrm{PO} \text { unit }]}
$$

where $V$ is the specific volume of the electrolyte solution, $M_{\mathrm{L}}$ and $M_{\mathrm{P}}$ are the molecular weights of $\mathrm{LiClO}_{4}$ and $\mathrm{PO}$ unit, respectively, $e$ is the charge of one ion, and $N$ is Avogadro's constant. The value reported by Moacanin et al. ${ }^{2}$ was used for $V$. If the dissociation of dissolved $\mathrm{LiClO}_{4}$ is complete, the $\mu$ value estimated from eq 1 agrees with the carrier mobility, and hence gives a lower limit of the carrier mobility.

Figure 3 shows the relation between $\mu$ and $\left[\mathrm{LiClO}_{4}\right] /[\mathrm{PO}$ unit]. The decrease in $\mu$ with an increase in $\left[\mathrm{LiClO}_{4}\right] /[\mathrm{PO}$ unit] corresponded to the increase in $\eta$ shown in Figure 2. This may be caused by a decrease in carrier mobility accompanying the increase in $\eta$. However, $\mu$ reached a maximum at a certain $\left[\mathrm{LiClO}_{4}\right] /[\mathrm{PO}$ unit], although $\eta$ increased monotonically. The appearance of the maximum $\mu$, therefore, can not be explained by viscosity effects alone.

The relation between $\mu$ and $1 / \eta$ at various salt concentrations is shown in Figure 4. Each set of data points can be represented by a straight line with a slope of 1.0. This indicated that the relation obeys the empirical Walden's rule ${ }^{7}$ :

$$
\mu \cdot \eta=\text { constant }
$$

The constant increased with an increase in salt concentration. Thus, on making a comparison between $\mu$ values at the same $1 / \eta$ a larger $\mu$ value will be found in a more concentrated solution.

\section{REFERENCES}

1. E. Santaniello, A. Manzocchi, and P. Sozzani, Tetrahedron Lett., 47, 4581 (1979).

2. J. Moacanin and E. F. Cuddihy, J. Polym. Sci., C, 14, 313 (1966).

3. R. E. Wetton, D. B. James, and W. Whiting, J. Polym. Sci., Polym. Lett. Ed., 14, 557 (1976).

4. M. Watanabe, J. Ikeda and I. Shinohara, Polymer J., 15, 65 (1983).

5. M. Watanabe, K. Nagaoka, M. Kanba and I. Shinohara, Polym. J., 14, 877 (1982).

6. H. Sasabe and S. Saito, Polym. J., 3, 624 (1972).

7. J. O'M. Bockris and A. K. N. Reddy, "Modern Electrochemistry," Vol. 1, Plenum Press, New York, 1970, Chapter 4. 